九州大学学術情報リポジトリ

Kyushu University Institutional Repository

\title{
Machine Learning-based Energy Management System for Prosumer
}

Gde Dharma Nugraha

Department of Electrical Engineering, Faculty of Engineering, Universitas Indonesia

Sudiarto, Budi

Department of Electrical Engineering, Faculty of Engineering, Universitas Indonesia

Ramli, Ka lamul lah

Department of Electrical Engineering, Faculty of Engineering, Universitas Indonesia

https://doi.org/10.5109/4055238

出版情報 : Evergreen. 7 (2)，pp.309-313，2020-06. 九州大学グリーンテクノロジー研究教育センター バージョン：

権利関係 : 


\title{
Machine Learning-based Energy Management System for Prosumer
}

\author{
Gde Dharma Nugraha ${ }^{1,2}$, Budi Sudiarto ${ }^{1}$, Kalamullah Ramli ${ }^{1, *}$ \\ ${ }^{1}$ Department of Electrical Engineering, Faculty of Engineering, Universitas Indonesia, 16424, \\ Indonesia \\ ${ }^{2}$ Digital Laboratory Department of Electrical Engineering, Faculty of Engineering, Universitas Indonesia, 16424, \\ Indonesia
}

*Author to whom correspondence should be addressed: E-mail: kalamullah.ramli@ui.ac.id

(Received December 5, 2019; Revised May 2, 2020; accepted May 21, 2020).

\begin{abstract}
The rapid development of RES technology produces cheaper and compact devices. This condition has attracted the household to install the RES devices on their premises. Hence, the household has changed from the passive electricity consumer into the active prosumer. The active prosumer not only consumes the electricity but also have the capability to produce electricity. However, the electricity produced by RES devices is intermittence and unstable. Moreover, the behavior of the inhabitants of the prosumer also changes over time. Hence, a smart energy management system is needed by the prosumer to maintain the balance of its electricity demand and supply. In this paper, we explore the integration of the Machine-learning based on the prosumer's EMS to address the uncertainty problem in the prosumer.
\end{abstract}

Keywords: Machine Learning, HEMS, Local Market, Prosumer, Energy Management System

\section{Introduction}

Nowadays, the rapid development of Renewable Energy Sources (RESs) technology has resulted in cheaper and compact devices ${ }^{1)}$. The cheaper and compact devices have attracted attention for the household to install it on their premises. With the RES devices installed on the household premises, the household has the capability to produce its energy. Then, the household is not only consuming energy from the grid but also can produce energy. The household with this capability is called the prosumer.

Being a prosumer offers various advantages ${ }^{2)}$. One of the advantages is saving electricity costs. Since the prosumer can produce its own electricity, the prosumer can reduce electricity purchases from the grid ${ }^{3}$. Moreover, the prosumer can sell its excess electricity to the grid or participate in the local electricity market to gain more profit ${ }^{4}$. In Indonesia, the capability of the prosumer to sell its electricity to the grid has been regulated by the Minister of Energy and Mineral Resources (ESDM) Regulation No 13/2019 5).

The presence of the prosumer has been known as one solution for sustainable energy ${ }^{6,7)}$. The presence of the prosumer can also play a role in increasing the level of electrification in Indonesia, especially for the rural areas and islands ${ }^{8)}$. The rural areas and islands in Indonesia still hard to get the electricity caused by the difficulties of rolling out the electricity infrastructure. So, being the prosumer is one of the alternatives to bring electricity to the household in rural areas and islands in Indonesia.

However, the prosumer has to maintain its own electricity demand and supply. The electricity produced by the RESs is unstable depends on the external factors, such as the weather condition. Meanwhile, the inhabitants of the prosumer also have different behavior over time. The instability of the RES and changes behavior of the inhabitants has challenged the balance of electricity demand and supply of the prosumer.

The energy management system (EMS) is one of the solutions to address the challenges of the prosumer. The EMS has the capability to manage the controllable loads of the prosumer. With the EMS, the prosumer can adjust its load to maintain the balance of the electricity demand and supply. The EMS can shift or change the load configuration so the demand can follow the condition of the electricity produced by the RES. However, this approach can sacrifice the comforts of the inhabitants. Hence, the integration of the machine learning module in the prosumer's EMS is indispensable.

In this paper, we design our machine-learning-based EMS for the prosumer. The proposed machine-learningbased EMS for the prosumer integrates the machine- 
learning module into the EMS to enable the prosumer's EMS to acknowledge the electricity production, consumption, and storage in advance and adjust the signal control intelligently. This paper is organized as follows; Section II presents the literature review regarding the EMS and its implementation for the prosumer. Section III explain our proposed machine-learning-based EMS, and section IV concludes our study.

\section{Literature Study}

The prosumer stands for the PROducer and conSUMER. It means that the prosumer is the electricity user who capable of producing and consuming electricity 9). The prosumer produces the electricity by utilizing the RES devices. However, electricity generation by the RESs is unstable, depends on the external factor such as the weather. Hence, the prosumer usually utilizes the electricity storage systems (ESS) to address the intermittence electricity of the RES. So the typical components of the prosumer are the RES device as the generator of electricity, the controllable loads to consume the electricity, and the ESS to store the electricity.

Recently, the EMS is used by the household or the building operator to maintain the balance of the electricity demand and supply ${ }^{10-13)}$. The EMS is used as part of the demand response system. The demand response system is the typical application to manage the electricity consumption of the household. The demand response system consists of two approaches, which are the pricebased and incentive-based approach. The price-based is the approach where the household willingly to reduce its electricity consumption when the price is high. Meanwhile, the incentive-based is the approach where the household can set a preference for its electricity reduction in advanced. The demand response system uses EMS as the tool to execute these approaches.

For the prosumer, the usage of the EMS becomes more complicated. The EMS not only has to manage the electricity consumption but also have to manage the electricity production and electricity storage ${ }^{2,9)}$. The prosumer has to monitor the electricity production of the RES and the electricity stored in the ESS while managing the controllable loads to maintain the electricity consumption of the prosumer. Furthermore, the prosumer can participate in the local electricity market to exchange its excess electricity. With this participation, the EMS of the prosumer has to define whether the prosumer has excess electricity or required more electricity.

The authors in ${ }^{12)}$ have proposed the EMS design for the prosumer. The proposed EMS design consists of four components. Figure 1 illustrated the components of the proposed EMS design. Figure 1 shows the interaction among the prosumer EMS and its components. The interaction among the prosumer and its components is bidirection with each direction has its own purpose.

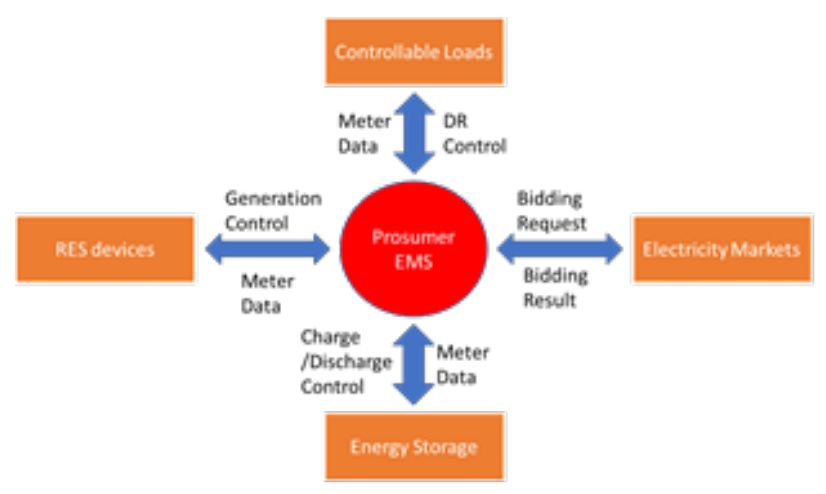

Fig. 1: Components of the Prosumer EMS

The EMS utilizes the smart meter to monitor the state of information regarding its controllable loads, RES device, and energy storage. In a different direction, the EMS sends the control signal for adjusting the control of each component. The electricity market is an optional component when the prosumer participates in the local electricity market ${ }^{14-16)}$. To the electricity market, the EMS will send its bidding request, whether to sell or purchase electricity. The bidding result then will send back from the electricity market to the EMS. The EMS will manage to send or to consume the electricity based on the bidding result.

Most recently, the advance development of smart meter technology provides an opportunity to record the electricity information at various time intervals ${ }^{17}$ ). The various time interval can be used to classify the smart meter data into three measurement classes, which are the on-demand class, scheduled class, and bulk measurement class ${ }^{18)}$. The on-demand measurement is the measurement that will be done by request from the system implemented by the prosumer, such as the EMS. The scheduled measurement is the automatic measurement where the smart meter collects the data at a specific time frequently $^{19)}$ (e.g., every 1 minute, 5 minutes, 10 minutes, etc.) while the bulk measurement is the measurement requested by the system to collect a set of data from the smart meter several times per day.

With this different time frequent, the smart meter data can be divided into historical data and streaming data ${ }^{20)}$. These two types of smart meter data can be used for different applications. The historical data can be used for offline data processing ${ }^{21}$, which produces the electricity profile of the prosumer while the streaming data can be used for detecting anomaly data or real-time events ${ }^{22)}$. Recent studies have been conducted to integrate these two data for machine learning algorithm ${ }^{23-25)}$. However, the integration into the prosumer's EMS is not considered yet. The integration of these two types of smart meter data may improve the performance of the prosumer's EMS to maintain the balance of electricity demand and supply.

From this EMS design, we can observe the responsibilities of the EMS of the prosumer. Until this stage, the prosumer's EMS can monitor the condition of 
each component and respond it through the control signal accordingly. However, this approach can sacrifice the comforts of the inhabitants of the prosumer. Moreover, when the prosumer participates in the local electricity trading, the prosumer's EMS has to maintain such an amount that agreed in the bidding result. It is hard for the prosumer's EMS to overcome this challenge without prior notice.

\section{Research}

In this paper, we propose to integrate the machine learning (ML) module into the EMS for the prosumer. The integration of the machine learning module to give the capability for the prosumer's EMS to maintain the balance of the electricity demand and supply of the Prosumer while maintaining the comforts of the inhabitants. The ML module also aims to support the EMS when the prosumer participates in the local electricity market. In the local electricity market, the prosumer can sell its excess electricity or purchase the electricity when the prosumer needs it.

\section{The Components of the Prosumer's EMS}

In this part, we describe components of the smart Prosumer's EMS. The components are driven by the data being processed by the ML module of the prosumer's EMS. The prosumer's EMS then takes a strategic decision based on the result of the ML module. As illustrated in Figure 1, the smart meter records the electricity information from the physical components of the prosumer's EMS. The module of the prosumer's EMS based on how the module process the smart meter data. The description of the proposed components for the prosumer's EMS as follows:

a. Batch module. The batch module is the ML module that processes historical smart meter data. The historical smart meter data is the smart meter data that already stored in the database. The result of this batch module is electricity forecasting for a certain period ahead. Electricity forecasting is essential for the prosumer's EMS to make a strategic decision regarding the operation of the prosumer's components. The historical smart meter data is used as the data source to create the electricity prediction model. The electricity prediction model can be configured for one-day ahead or even for one-hour ahead. The one-day ahead prediction model will be used to generate the strategic decision, for example, which controllable load should be turn off or turn on at a particular time. This strategic decision also can be used to acknowledge the amount of excess electricity or the required electricity at a particular time. This information than can be used by the prosumer's EMS when participating in the local electricity market.

b. Streaming module. The streaming module is the module that processes the smart meter data that just recorded by the smart meter. The smart meter can record the electricity data in different frequent times. Hence, the smart meter data can be recorded near real-time. The real-time smart meter data is vital to recognize any real-time event. The streaming module compares the real-time smart meter data with the prediction model from the batch layer to recognize this real-time event. With this capability, the prosumer's EMS can anticipate any real-time event to avoid any harmful condition to the prosumer.

c. ML-based control. The ML-based control module is the module that has control access to the controllable loads. The ML-based control module uses the strategic decision from the batch layer and real-time event detection from the streaming layer to execute any control schema to adjust the controllable loads accordingly. With this ML-based control module, the electricity usage of the controllable loads can be adjusted without sacrificing the comfort of the inhabitants of the prosumer.

The ML-based module of the prosumer's EMS is illustrated in Figure 2.

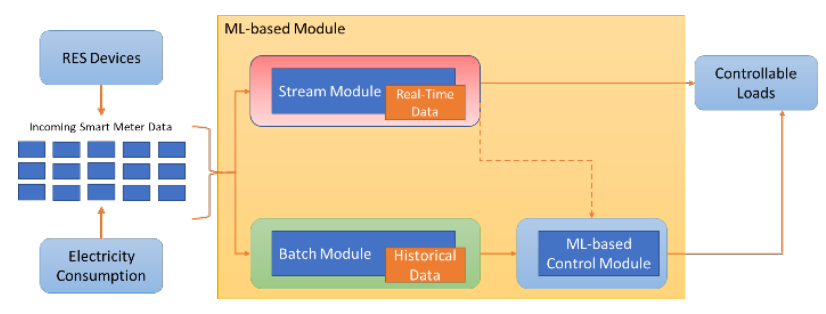

Fig. 2: The proposed ML-based module of the prosumer's EMS.

\section{The ML Algorithm for the ML-based Prosumer's EMS}

Several ML algorithms can be used for the ML-based Prosumer's EMS. Some of these ML algorithms are the forecasting algorithm and anomaly detection algorithms.

a. The forecasting algorithm

For the forecasting algorithm, the smart meter data is treated as the time-series data. The algorithm that widely used for the forecasting algorithm is the ARIMA. ARIMA stands for AutoRegressive Integrated Moving Average. The ARIMA composed of components, which are the AR (Auto-Regressive), I (Integrated), and MA (Moving Average). The formula to calculate the ARIMA as follows:

$$
\nabla^{d} X_{t}=\sum_{i=1}^{q} \beta_{i} \varepsilon_{t-i}+\sum_{i=1}^{k} \alpha_{i} \nabla^{d} X_{t-1}+\varepsilon_{t}
$$

The AR component computes the effect of past time 
points of time series data on current and future time points. Autoregression function is denoted by $A R(p)$, which satisfies $X_{t}=\sum_{i=1}^{p} \alpha_{i} \mid X_{t-1}+\varepsilon_{t}$. The I component is denoted by parameter $d$. The $d$ represents the degree of differencing in the integrated component. The process in this component is merely subtracting its current and previous values $d$ times. The MA component is denoted by the parameter $q$, which utilizes the error terms of previous time points to predict current and future time points.

b. Anomaly detection algorithm

The anomaly detection algorithm compares the data with the prediction model. If the difference between the data and the prediction model is more than the defined limits, the data can be said as the anomaly data. This anomaly data represents any real-time events that have to be anticipated by the prosumer's EMS.

One algorithm used for anomaly detection algorithm is the density-based anomaly detection. This algorithm is based on the k-nearest neighbors' algorithms. This algorithm assumes that the normal data occur around a dense neighborhood, and the anomaly data are far away. The Euclidean distance is used to measure the distance of the data from the center of the dense data.

\section{Conclusion}

The Machine-learning based on Prosumer's EMS is proposed in this paper. Based on the way to process the smart meter data, this paper proposes three modules for the prosumer's EMS. The batch module, the speed module, and the ML-based control module. With this module, the prosumer's EMS can adjust the configuration of the controllable loads to follow the configuration from the ML module while maintaining the comfort of the inhabitants of the prosumer.

\section{Acknowledgments}

Thank you to the Ministry of Technology and Higher Education and the Universitas Indonesia for financial support through the 2018 Penelitian Dasar Unggulan Perguruan Tinggi (PDUPT) scheme with Contract Number 1/E1/KP.PTNBH/2019, 234/PKS/R/UI/2019.

\section{References}

1) M. Scheepers, and M. Van Werven, "Distributed generation in electricity markets, its impact on distribution system operators , and the role of regulatory and," Int. J. Distrib. Energy Resour., 2 (1) 7138-7138 (2006).

2) E. Espe, V. Potdar, and E. Chang, "Prosumer communities and relationships in smart grids: a literature review, evolution and future directions," Energies, 11 (10) (2018). doi:10.3390/en11102528.

3) O. Jogunola, A. Ikpehai, K. Anoh, B. Adebisi, M. Hammoudeh, S.Y. Son, and G. Harris, "State-of-the-art and prospects for peer-topeer transaction-based energy system," Energies, $10 \quad$ (12) 1-28 (2017). doi:10.3390/en10122106.

4) N. Liu, X. Yu, C. Wang, C. Li, L. Ma, and J. Lei, "An energy-sharing model with price-based demand response for microgrids of peer-topeer prosumers," IEEE Trans. Power Syst., 32 (5) 3569-3583 (2017). doi:10.1109/TPWRS.2017.2649558.

5) Menteri ESDM RI, "Peraturan menteri esdm ri nomor 13 tahun 2019," (2019).

6) M.K. Barai, and B.B. Saha, "Energy security and sustainability in japan," Evergreen, 2 (1) 49-56 (2015). doi:10.5109/1500427.

7) T. Sato, "How is a sustainable society established? a case study of cities in japan and germany," Evergreen, 3 (2) 25-35 (2016). doi:10.5109/1800869.

8) PT. Perusahaan Listrik Negara, "Rencana usaha penyediaan tenaga listrik," Rencana Usaha Penyediaan Tenaga List., 2019-2028 (2019).

9) R. Zafar, A. Mahmood, S. Razzaq, W. Ali, U. Naeem, and K. Shehzad, "Prosumer based energy management and sharing in smart grid," Renew. Sustain. Energy Rev., 82 (August 2016) 1675-1684 (2018). doi:10.1016/j.rser.2017.07.018.

10) M. Amer, A. Naaman, N.K. M'Sirdi, and A.M. El-Zonkoly, "Smart home energy management systems survey," Int. Conf. Renew. Energies Dev. Ctries. 2014, 167-173 (2014). doi:10.1109/REDEC.2014.7038551.

11) M. Beaudin, and H. Zareipour, "Home energy management systems: a review of modelling and complexity," Renew. Sustain. Energy Rev., 45 318-335 (2015). doi:10.1016/j.rser.2015.01.046.

12) B. Zhou, W. Li, K.W. Chan, Y. Cao, Y. Kuang, $\mathrm{X}$. Liu, and X. Wang, "Smart home energy management systems: concept, configurations, and scheduling strategies," Renew. Sustain. Energy Rev., $61 \quad 30-40 \quad$ (2016). doi:10.1016/j.rser.2016.03.047.

13) M. Manic, D. Wijayasekara, K. Amarasinghe, and J.J. Rodriguez-Andina, "Building energy management systems: the age of intelligent and adaptive buildings," IEEE Ind. Electron. Mag., (March) 25-39 (2016). doi:10.1109/MIE.2015.2513749.

14) C. Long, J. Wu, C. Zhang, M. Cheng, and A. AlWakeel, "Feasibility of peer-to-peer energy trading in low voltage electrical distribution 
networks," Energy Procedia, 105 2227-2232 (2017). doi:10.1016/j.egypro.2017.03.632.

15) A. Lüth, J.M. Zepter, P. Crespo del Granado, and R. Egging, "Local electricity market designs for peer-to-peer trading: the role of battery flexibility," Appl. Energy, 229 (August) 1233-1243

(2018). doi:10.1016/j.apenergy.2018.08.004.

16) O. Jogunola, A. Ikpehai, K. Anoh, B. Adebisi, M. Hammoudeh, H. Gacanin, and G. Harris, "Comparative analysis of $\mathrm{p} 2 \mathrm{p}$ architectures for energy trading and sharing," Energies, 11 (1) 1-20 (2018). doi:10.3390/en11010062.

17) Y. Kabalci, "A survey on smart metering and smart grid communication," Renew. Sustain. Energy Rev., $57 \quad 302-318 \quad$ (2016). doi:10.1016/j.rser.2015.12.114.

18) M. Kuzlu, M. Pipattanasomporn, and S. Rahman, "Communication network requirements for major smart grid applications in han, nan and wan," Comput. Networks, $67 \quad 74-88 \quad$ (2014). doi:10.1016/j.comnet.2014.03.029.

19) P. Sieverts, and E. Systems, "Streamlining smart meter data analytics," (2015).

20) D. Alahakoon, and X. Yu, "Smart electricity meter data intelligence for future energy systems: a survey," IEEE Trans. Ind. Informatics, 12 (1) 425-436 (2016). doi:10.1109/TII.2015.2414355.

21) A. Mellit, and A.M. Pavan, "A 24-h forecast of solar irradiance using artificial neural network: application for performance prediction of a grid-connected pv plant at trieste, italy," Sol. Energy, 84 (5) 807-821 (2010). doi:10.1016/j.solener.2010.02.006.

22) A. Laouafi, M. Mordjaoui, S. Haddad, T.E. Boukelia, and A. Ganouche, "Online electricity demand forecasting based on an effective forecast combination methodology," Electr. Power Syst. Res., 148 35-47 (2017). doi:10.1016/j.epsr.2017.03.016.

23) X.L. B, N. Iftikhar, P.S. Nielsen, and A. Heller, "Online anomaly energy consumption detection using lambda architecture," Int. Conf. Big Data Anal. Knowl. Discov. Springer, 193-209 (2016). doi:10.1007/978-3-319-439464.

24) G.D. Nugraha, A. Musa, J. Cho, K. Park, and D. Choi, "Lambda-based data processing architecture for two-level load forecasting in residential buildings," Energies, 11 (4) (2018). doi:10.3390/en 11040772.

25) A.A. Munshi, and Y.A.R.I. Mohamed, "Data lake lambda architecture for smart grids big data analytics," IEEE Access, 6 40463-40471 (2018). doi:10.1109/ACCESS.2018.2858256. 